Nevşehir Bilim ve Teknoloji Dergisi Cilt 4(1) 34-44 2015

DOI: 10.17100/nevbiltek.210940

URL: http://dx.doi.org/10.17100/nevbiltek.210940

\title{
Ayvacık Barajı (Çanakkale) Alburnus chalcoides (Güldenstädt, 1772) Populasyonuna Ait Parametrelerin Belirlenmesi
}

\author{
Erdoğan Çiçek $^{1 *}$, Sevil Birecikligil ${ }^{1}$, Orhan Yavuz ${ }^{1}$, Burak Seçer ${ }^{1}$, S. Batuhan Keskin ${ }^{1}$ \\ ${ }^{1}$ Nevşehir Hacı Bektaş, Veli Üniversitesi, Fen Edebiyat Fakültesi, Biyoloji Bölümü, Nevşehir \\ $\ddot{O} \mathbf{z}$
}

Bu çalışma, Ayvacık Barajı Alburnus chalcoides populasyonuna ait parametrelerin belirlenmesi amacıyla Ağustos-Kasım 2014 tarihleri arasında gerçekleştirilmiş olup toplam 726 birey incelenmiştir. İncelenen bireylerin yaşlarının 0-IV'üncü yaş grubu arasında olduğu; örneklenen bireylerin boy değerlerinin 6,0 ile 21,7 cm $(10,63 \pm 2,43 \mathrm{~cm})$ ve ağırlıklarının ise 1,58 ile 90,20 g $(11,63 \pm 9,47 \mathrm{~g})$ arasında değişim gösterdiği belirlenmiştir. Boy-ağırlık ilişkisi ise $W=0,00705 L^{3,0528}$ olarak belirlenmişsir. Populasyon parametreleri akarsular için $L_{\infty}: 32,81 \mathrm{~cm}, k: 0,140, t_{0}:-1,38, \Phi^{\prime}: 2,18$ ve $K: 0,76$ olarak hesaplanmıştır. Ölüm oranları ve stoktan yararlanma düzeyi ise $Z: 0,646, M: 0,325, F: 0,321$ ve $E: 0,497$ olarak tahmin edilmiştir. Tahmin edilen bu değerler 1şı̆̆ında popülasyon üzerinde aşırı avcılık baskısının bulunmadığı ve stoktan optimum düzeyde yararlanıldığı söylenebilir.

Anahtar Kelimeler: Tatlı su kolyoz balığı, Alburnus chalcoides, Ölüm oranları, Ayvacık Barajı, Çanakkale

\section{Determination of Population Parameters of Alburnus chalcoides (Güldenstädt, 1772) From Ayvacık Dam Lake (Çanakkale)}

Abstract

This study was carried out in order to determine population parameters of Alburnus chalcoides between August and November 2014 in Ayvacık Dam Lake and a total of 727 specimens analyzed. Age of the specimens ranged from 0 to IV. age groups. Total length and total weight varied from 6.0 to $21.7 \mathrm{~cm}(10.63 \pm 2.43 \mathrm{~cm})$ and 1.58 to $90.20 \mathrm{~g}(11.63 \pm 9.47 \mathrm{~g})$, respectively. Length-weight relationship were estimated $W=0.00705 L^{3.0528}$. Estimated population parameters were calculated as $L_{\infty}: 32.81 \mathrm{~cm}, k: 0.140, t_{0}:-1.38$, $\Phi^{\prime}: 2.18$ and $K$ : 0.76 for the population. Mortality and exploitation rates also estimated as Z: 0.646, M: 0.325, F: 0.321 and E: 0.497, respectively. In the light of these values have been estimated there were not any over fishing pressure on the population which is exploited optimally.

Keywords: Caspiyan shemaya, Alburnus chalcoides, Mortality rates, Ayvacık Dam Lake, Çanakkale

*e-mail:erdogancicek@nevsehir.edu.tr 


\section{Giriș}

Barajlar çok eski zamanlardan beri insanların, içme veya tarımsal su ihtiyacının karşılanması, taşkın önleme, enerji elde edilmesi gibi değişik ihtiyaçlarının karşılanması amacıyla akarsular üzerine inşa edilen su yapılarıdır. Barajlar kurulma sebebi olan işlevlerinin yanı sıra su ürünleri üretimi açısından da önemli bir potansiyel oluşturmaktadırlar. Lotik ekosistemler olan akarsular üzerine barajların kurulması ile lentik ekosistemler haline gelirler. Bu potansiyelin kullanılması amaciyla durgun su kütleleri için uygun ve ekonomik önemi yüksek olan türlerde balıklandırma yoluna gidilmektedir [1]. Nitekim Türkiye’de de göl, gölet ve baraj göllerinde zaman zaman veya periyodik olarak yapılan balık aşılama çalışmaları ile sucul ortamların balık stoklarının zenginleştirilmesi amaçlanmıştır [2]. Bu türlerden bir tanesi de, Tatlı Su Kolyoz Balığı, Alburnus chalcoides, türüdür.

Türkiye'de doğal olarak Kura-Aras Havzasında dağılım gösteren bu tür sportif ve/veya ticari balıkçılık amacıyla balıklandırma yoluyla bazı barajlara taşınmıştır [3]. Ancak balıklandırma sonucu farklı su kütlelerine taşınmış olan pek çok tür ile ilgili kayıt olmadığı gibi bu tür için de böyle bir veri bulunmamaktadır. Daha önce yapılmış olan bilimsel çalışmalarda verilen kayıtlara göre türün Türkiye'de farklı bölgelerdeki barajlarda ve doğal göllerde dağılım gösterdiği anlaşılmaktadır [3-6].

Çalışmanın yürütüldüğü Ayvacık Barajında, ne suyun fiziko-kimyasal özellikleri ne de barajın biyolojik elementleri ile ilgili yapılmış olan herhangi bir çalışmaya rastlanmamıştır.

Balık türlerinin morfolojik karakterleriyle tanımlanması, popülasyona ait yaş, boy ve ağırlık dağılımlarının belirlenmesi; elde edilen veriler yardımıyla büyüme parametrelerinin ve parametreler arasındaki ilişkilerin belirlenerek ölüm oranları ve stoktan yararlanma düzeylerinin ortaya konması balıkçılık biyolojisi ve populasyon dinamiği çalışmalarının temelini oluşturur. Ancak balıklarda büyüme ve gelişme çevresel faktörlerle sıkı sıkıya ilişki içerisinde olup bölgeden bölgeye ve hatta aynı popülasyonda yıldan yıla bile değişiklikler gözlemlenebilir. Bu nedenle insan eliyle farklı bölgelere taşınan türlerin dağılımlarının bilinmesi, farklı bölgelerde oluşturdukları populasyona ait biyo-ekolojik özellikleri ve populasyon parametrelerinin belirlenmesi büyük önem taşımaktadır.

Bu çalışmada Ayvacık Barajında yaşayan Alburnus chalcoides türü popülasyonuna ait yaş, büyüme ve ölüm parametrelerinin belirlenmesi amaçlanmıştır.

Gerek doğal dağılım alanı ve gerekse taşınıldıkları alanlarda, A. chalcoides popülasyonuna ait bazı parametreler daha önceki çalışmalarda belirlenmiştir. Akyurt ve Sarı [7] Tozanlı Çayı (Tokat), Balık ve Sarı [8] Demirköprü Barajı, Balık ve ark. [9] Kuş Gölü, Ünver ve Saraydın [10] Tödürge Gölü, Tarkan ve ark. [11] Ömerli Barajı, Başdemir [12] Gönen Çayı, Ünver ve Erk’akan [4] Tödürge Gölü, Balaban [6] Manyas Kuş Cenneti, Başdemir ve ark. [13] Çakırköy Deresi (Yenice-Çanakkale), Yılmaz ve Suiçmez [5] Almus Baraj Gölü ve Dirican ve Çilek [14] Çamlıöze Baraj Gölü popülasyonuna ait populasyon parametrelerini belirlemişlerdir. Bunun yanı sıra türün dağılım gösterdiği ülkelerde de türün büyüme [1517], üreme [18] ve morfolojik özellikleri [19-22].

\section{Materyal ve Yöntem}

Çanakkale ili Ayvacık ilçesi sınırları içerisinde yer alan baraj (N 39,60825038, E 26,47837086) Tuzla Çayı üzerine kurulmuş olup yapımına 2002 yılında başlanmış ve 2008 yılında işletmeye alınmıştır. 
Sulama ve içme suyu amaçlı olarak kullanılan baraj kil çekirdekli kum-çakıl dolgu gövdelidir. Normal su kotundaki $39 \mathrm{hm}^{3}$ olup normal su kotunda göl alanı 3,42 km²,dir.

Alburnus chalcoides (Güldenstädt, 1772): İlk tanımlandığında Chalcarburnus cinsi altında yer alan tür daha sonraki çalışmalara dayanarak Alburnus cinsinde dahil edilmiştir [23]. Diğer Alburnus türlerinde olduğu gibi siyah bir bant bulunmaz [24]. Tür tayini Geldiay ve Balık [24] ile Kottelat ve Freyhof [25] tarafından verilmiş olan tanımlayıcı özellikler kullanılmıştır.

Doğal olarak Hazar Denizi, Aral Gölü ve Karadeniz havzalarındaki akarsu sistemlerinde ve göllerde geniş bir dağılıma sahiptir. Balıklandırma yoluyla istemli ve istemsiz olarak doğal yayılım alanı olan Aras Havzası dışında Türkiye'nin farklı bölgelerine de aşılanmıştır.

Üremelerini küçük akarsu sistemlerinin üst kısımlarına göç ederek yapar [24]. Ancak kapalı rezervuar alanlarda rezervuara giriş yapan akarsu kollarında üredikleri bildirilmektedir [25]. Türkiye'nin farklı bölgelerinde üreme zamanı Mayıs-Temmuz olarak bildirilmektedir [26,27]. Bu türün habitat kaybı, kirlilik ve ötrofikasyon, akarsular üzerine inşa edilen setler/barajlar gibi nedenlerle tehdit altında olduğu bildirilmektedir [28].

Ekonomik öneme sahip olmayan bir türdür. Ancak bölgesel olarak, uzatma ağları ve sportif avcılıkta olta ile avlanıp besin olarak tüketilmektedir. Beslenme özelliği bakımından besin zincirinin alt halkalarında yer alan canlı gruplarıyla beslenen A. chalcoides'in ekosistemde besin piramidinin üst basamaklarına enerji ve maddenin aktarılması bakımından önemli bir işlevi vardır.

Örneklerin toplanması amacıyla saha çalışmaları 04-05.09.2014 ve 01-02.11.2014 tarihlerinde iki defa olmak üzere gerçekleştirilmiştir. Örneklemede TS EN 14757 (Su Kalitesi-Değişen Göz Açıklıklı Sık Örgülü Ağlarla Balık Numunesi Alınması) standartlarında belirtilen yöntemler esas alınmıştır. Buna göre 30,0 m uzunluğunda ve 1,5 m derinliğinde, her biri 2,5 m uzunluğa sahip, 12 farklı göz açıklığında (5x5; 6,25x6,25; 8x8; 10x10; 12,5x12,5; 15,5x15,5; 19,5x19,5; 24x24; 29x29; 35x35; 43x43; 55x55 mm) panellerin birleştirilmesiyle oluşturulmuş dip ağları ve yine her biri $2,5 \mathrm{~m}$ uzunluğunda 11 farklı göz açıklığına sahip $(6,25 \times 6,25 ; 8 \times 8 ; 10 \times 10 ; 12,5 \times 12,5 ; 15,5 \times 15,5 ; 19,5 \times 19,5 ; 24 \times 24 ; 29 \times 29 ; 35 \times 35 ; 43 \times 43$; $55 \times 55 \mathrm{~mm}$ ) panellerden oluşan 27,5 m uzunluğunda $6 \mathrm{~m}$ derinliğinde pelajik ağlar kullanılarak örnekleme yapılmıştır. Ağlar gün batmadan atılmış ve gün doğumundan sonra toplanmış olup en az 12 saat suda kalmıştır.

Arazi çalışmaları sırasında elde edilen örnekler \%4'lük formaldehit çözeltisi içeren plastik bidonlar içerisine konarak muhafaza edilmiş ve Nevşehir Hacı Bektaş Veli Üniversitesi, Biyoloji Bölümü, Hidrobiyoloji Araştırma Laboratuvarına getirilmiştir.

Laboratuvara getirilen örneklerin tür tayinleri Geldiay ve Balık [24] tarafindan verilen teşhis anahtarları kullanılarak yapılmıştır. Laboratuvarda teşhisi yapılmış olan örneklerin total boy ölçümleri 1 $\mathrm{mm}$ hassasiyetle dijital kumpas ve ağırlıkları ise $0,01 \mathrm{~g}$ hassasiyetli elektronik hassas terazi kullanılarak belirlenmiştir. Yaş tayininin belirlenmesi amacıyla, balıkların vücutlarının yan kısımlarındaki pullarının çoğu dökülmüş olduğundan, dorsal yüzgeç civarından pul örnekleri alınarak doğrudan 1şık mikroskobu altında X40 büyütmede yaş halkaları sayılmıştır.

Boy-ağırlık ilişkisinin belirlenmesinde Regresyon Yönteminden yararlanılarak $W=a L^{b}$ eşitliği ile ifade edilmiştir [29]. Bu eşitlikte; $W=$ total ağırlık (g), $a$ ve $b=$ regresyon sabitleri ve $L=$ : total boyu (cm) göstermektedir. Boy ve ağırlıkça büyümenin matematiksel olarak incelenmesinde von 
Bertalanffy'nin boyca ve ağırlıkça büyüme eşitliği kullanılmıştır [29]: $L_{t}=L_{\infty}\left[1-e^{-k(t-t o)}\right]$ ve $W_{t}=W_{\infty}\left[1-e^{-k(t-}\right.$ ${ }^{\text {to) }}$ ]. Bu eşitlikte; $L t=$ : t'inci yaştaki balığın boyu $(\mathrm{cm}), L_{\infty}=$ Sonuşmaz uzunluğu $(\mathrm{cm}), W_{\infty}=$ Sonuşmaz ağırlık (g), $k=$ Brody'nin büyüme katsayısı $\left(\mathrm{yl}^{-1}{ }^{-1}\right)$ ve $t_{0}=$ balığın yumurtadan çıktığı andaki kuramsal yaşını (yıl) ifade etmektedir [29].

Balıklarda büyüme oranının karşılaştırılmasında kullanılan büyüme performans indeksi $\Phi^{\prime}=\log k+2 \log L_{\infty}$ formülden yararlanılarak belirlenmiştir [29]. Bu eşitlikte; $\Phi=$ büyüme performans indeksini, $L_{\infty}=$ Sonuşmaz uzunluğu $(\mathrm{cm}), k=$ Brody'nin büyüme katsayısını $\left(\mathrm{yl}^{-1}{ }^{-1}\right)$ göstermektedir.

Balıklarda besililik düzeyinin için ise Fulton’un Kondisyon Faktörü $\left(K=100 \frac{W}{L^{b}}\right)$ hesaplanmış ve bunların aritmetik ortalaması alınmıştır [30]. Bu eşitlikte; $W=$ total ağırlık $(\mathrm{g}), L=$ total boy $(\mathrm{cm})$ ve $b=$ regresyon sabitini göstermektedir.

Toplam ölümlerin üssi katsayısının $(Z)$ hesaplanmasında Beverton ve Holt tarafindan önerilen ortalama boy değeri kullanılmıştır [31]. $Z=k \frac{\left(L_{\infty}-\bar{L}\right)}{\left(\bar{L}-L^{\prime}\right)}$ Bu eşitlikte; $Z=$ toplam ölümlerin üssi katsayısı, $L_{=}$ sonuşmaz uzunluğu $(\mathrm{cm}), \bar{L}=$ incelenen bireylerin ortalama boyu $(\mathrm{cm}), \bar{L}=$ incelenen bireylerden en küçük boylu balıkların bulunduğu sınıf aralığı $(\mathrm{cm})$ ve $k=$ Brody'nin büyüme katsayısını (yı1 ${ }^{-1}$ ) göstermektedir. Doğal nedenlerle olan ölüm oranlarının üssi katsayısı $(M)$ Pauly’nin deneysel formülüne dayanılarak hesaplanmıştır [32]: $\log 10 M=-0,0152-0,279 \log 10 L_{\infty}+0,6543 \log 10 k+0,463 \log 10 T$. Bu eşitlikte; $T=$ incelenen popülasyonun yaşadığı yıllık ortalama su sıcaklı̆̆ını $\left({ }^{\circ} \mathrm{C}\right)$ göstermektedir. Barajda daha önce yapılmış olan bilimsel bir çalışma bulunmadığından yıllık ortalama su sıcaklığına ait herhangi bir veriye de rastlanmamıştır. Bu nedenle, farklı çalışmaların incelenmesi sonucunda, söz konusu formülde su sıcaklığının tahmini bir değer olarak $12,0^{\circ} \mathrm{C}$ kabul edilmesine karar verilmiştir [33].

Balıkçılık nedeniyle olan ölümlerin üssi katsayısı $(F)$ belirlenmesinde ise toplam ölüm oranı ile doğal ölümler arasındaki farktan yararlanılmıştır [29]. F=Z-M. Stoktan yararlanma düzeyinin belirlenmesi için, sömürülme oranı popülasyon için belirlenmiş olan ölüm oranları kullanılarak $E=\frac{F}{Z}$ eşitliği kullanılarak hesaplanmıştır.

Tez çalışması boyunca ham verilerin düzenlenmesi, grafiklerin oluşturulmasında Microsoft Excel programı kullanılmıştır.

Yaş tayininin yapılması amacıyla pullar iki farklı kişi tarafindan okunmuştur. İki okuma arasındaki uyum \% olarak tespit edilmiştir.

Ölçülen ve eşitlikler yardımıyla hesaplanan boy ve ağırlık değerleri arasında istatistiksel anlamda herhangi bir farkın olup olmadığı Khi Kare $\left(X^{2}\right)$ Testi ile belirlenmiştir.

\section{Bulgular ve Tartışma}

Bu çalışmada elde edilen 726 birey incelenmiş ve 400 bireyden yaş tayini yapılmıştır. Buna göre bireylerin 0-IV. yaş grupları arasında değişim gösterdiği, 0. yaş grubunun en baskın $(\% 53,50)$ yaş grubu olduğu bunu sırasıyla \%36,25 ve \%9,50’lik bir değerlerle I. ve II. yaş gruplarının izlediği ve yaş ilerledikçe frekans değerinin ani azalış gösterdiği görülmüştür. Daha önceki çalışmalarda VII yaşına kadar bireylere rastlandığı ve Tödürge Gölü, Çakırköy Deresi ve Almus Baraj Gölü popülasyonları için baskın olan yaş grupları sırasıyla III. $(\% 65,2)$, I. $(\% 52,63)$ ve II. yaş grubu $(\% 65,70)$ olarak bildirilmiştir [4, 5, 12]. Tarkan ve ark. [11] Ömerli Barajında incelenen bireylerin \%70'den fazlasının II ve altı yaş 
gruplarına dahil olduklarını rapor etmişlerdir. Ayvacık Barajı popülasyonunda bireylerin büyük çoğunluğunun $(\% 89,75) 0$ ve I'inci yaş gruplarına ait belirlenmiştir.

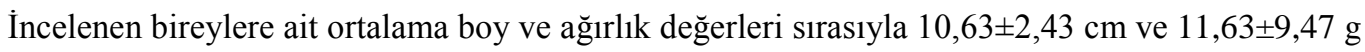
olarak hesaplanmıştır (Tablo 1). Örneklenen bireylerde $9 \mathrm{~cm}$ boy grubunun en baskın boy grubu olduğu $(\% 30,6)$ bunu \%19,3’lük bir oranla $8 \mathrm{~cm}$ boy grubunun izlediği ve popülasyonun \%69,83’ünün $10 \mathrm{~cm}$ ve daha küçük boylu bireylerden oluştuğu görülmektedir. En yüksek boyca büyüme oranının 0-I'inci yaşlar arasında olduğu, takip eden yaşlarda ise büyümenin oransal olarak azalış gösterdiği tespit edilmiştir.

Tablo 1. Ayvacık Barajı Alburnus chalcoides popülasyonuna ait yaş, boy ve ağırlık frekans dağılımı ile her yaş için ortalama boy ve ağırlık değerleri

\begin{tabular}{|c|c|c|c|c|c|c|c|}
\hline \multirow[b]{2}{*}{ Yaș } & \multirow[b]{2}{*}{$\mathbf{N}$} & \multirow[b]{2}{*}{$\% n$} & \multicolumn{3}{|c|}{ Total Boy (cm) } & \multicolumn{2}{|c|}{ Total Ăğırlık (g) } \\
\hline & & & $\begin{array}{c}\text { Ortalama } \\
\text { Boy }\end{array}$ & Değişim Aralığı & $\begin{array}{c}\text { Büyüme } \\
\text { Oranı (\%) }\end{array}$ & $\begin{array}{c}\text { Ortalama } \\
\text { Ağırlık }\end{array}$ & $\begin{array}{c}\text { Değgişim } \\
\text { Aralığı }\end{array}$ \\
\hline 0 & 214 & 53,50 & $8,82 \pm 0,75$ & $6,0-10,6$ & & $5,58 \pm 2,43$ & $2,10-14,30$ \\
\hline I & 145 & 36,25 & $12,12 \pm 1,63$ & $8,0-14,9$ & 37,41 & $15,56 \pm 5,92$ & $3,92-32,52$ \\
\hline II & 38 & 9,50 & $14,52 \pm 1,32$ & $11,8-18,5$ & 19,80 & $24,65 \pm 9,25$ & $12,98-55,30$ \\
\hline III & 1 & 0,25 & 16,9 & - & 16,39 & 48 & - \\
\hline IV & 2 & 0,50 & $19,1 \pm 3,68$ & $16,5-21,7$ & 13,02 & $66,04 \pm 34,17$ & $41,88-90,20$ \\
\hline$\Sigma$ & 726 & & $10,63 \pm 2,43$ & $6,0-21,7$ & & $11,63 \pm 9,47$ & $1,58-90,20$ \\
\hline
\end{tabular}

Daha önce yapılmış olan çalışmalarda ortalama boy ve ağırlık dağılımları Tozanlı Çayı için 10,516,0 cm/13-48 g [7], Kuş Gölü için 5,2-21,4 cm/1-160 g [9], Ömerli Baraj Gölü için 7,2-28,0 cm [11], Gönen Çayı için 6,1-16,0 cm/2,5-54,6 g [12], Tödürge Gölü için 8,6-26,2 cm/6,0-219,8 g [4], Manyas Kuş Cenneti için 3,2-16,0 cm/0,6-65,8 g Balaban [6], Çakırköy Deresi için 6,1-16,0 cm/2,5-54,6 g [13] ve Almus Baraj Gölünde ise 10,8-18,8 cm/11-67 g [5] arasında değişim gösterdiği rapor edilmektedir. Bu çalışmada ise bu değerlerin 6,0-21,7cm/1,58-90,20 g arasında değişim gösterdiği belirlenmiştir.

Popülasyon dinamiği çalışmalarında kullanılan bireylerin boy dağılım frekansı ve buna bağlı olarak yaş ve ağırlık dağılımları uygulanan örnekleme yöntemine bağlı olarak değişiklik göstermektedir. Seçiciliği yüksek olan av araçları ile yapılan örneklemelerde küçük balıklar seçilmesi nedeniyle örnekte yeteri kadar temsil edilmemektedir. $\mathrm{Bu}$ nedenle farklı bölge popülasyonlarının boy dağılımlarını kıyaslamak objektif bir yaklaşım olmayacaktır.

Göllerde farklı göz açıklıklarına sahip ağlar kullanılmasına rağmen hem küçük ve hem de büyük boylu bireylerin seçilimi söz konusudur. Akarsulardan yapılan örneklemede de, farklı boy gruplarına ait bireylerin akarsuyun değişik bölgelerinde dağılım göstermesi, kullanılan av aracının seçiciliği vb. gibi sebeplerden dolayı yine bir seçilimden bahsedilebilir. Bu nedenle farklı bölgelerde yapılan çalışmalar arasında yaş dağılımı ve buna bağlı olarak boy ve ağırlık dağılımlarında da farklılık görülmesi doğaldır. Nitekim seçiciliği olan av araçları ile yapılan örneklemelerde yaş, boy, ağırlık vb. gibi değişkenlerin farklılık göstereceği ve bunlara bağlı olarak hesaplanan popülasyon parametreleri arasında da farklılıklar görülebileceği aşikardır [34]. 
Türkiye’de tatlı su balıkları ile ilgili yapılan popülasyon dinamiği çalışmalarında çatal boy değerlerinin kullanıldığı görülmüştür. $\mathrm{Bu}$ nedenle farklı çalışmalarda elde edilen sonuçların karşılaştırılması ve yorumlamasında kolaylık olması bakımından birliktelik sağlamak amacıyla total boyçatal boy ilişkisi $(\mathrm{ÇB}=(0,9374 * \mathrm{~TB})-1,9924)$ ve total boy-standart boy arasındaki ilişki $(\mathrm{SB}=(0,866$ *TB)3,1849) tahmin edilmiştir.

Ayvacık Barajı A. chalcoides popülasyonu için belirlenmiş olan boy-ağırlık ilişkisi $W=0,007051 L^{3,0528}$ olarak belirlenmiştir (Şekil 1). Yapılan Regresyon Analizi sonucunda b değerinin \%95 güven aralığı 3,003-3,103 olarak belirlenmiş olup büyümenin pozitif allometrik bir yapı sergilediği görülmüştür.

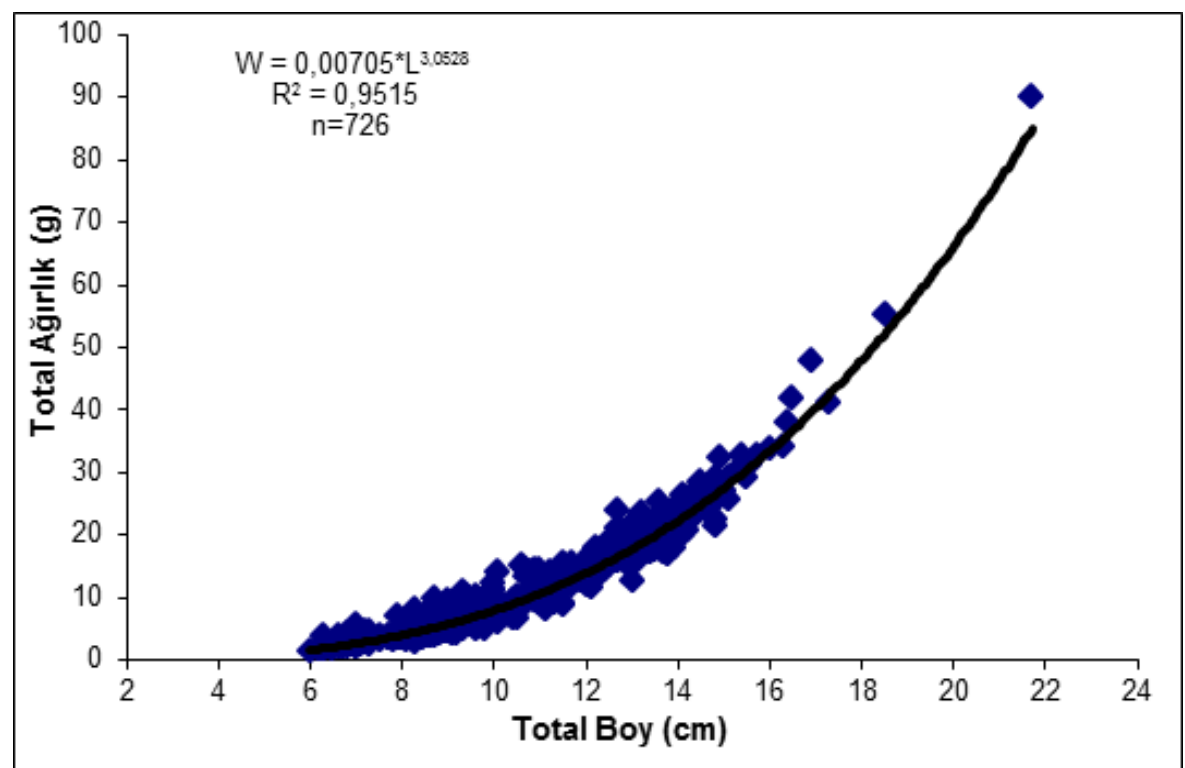

Şekil 1. Ayvacık Barajı Alburnus chalcoides popülasyonuna ait boy-ağırlık ilişkisi grafiği

A. chalcoides'in popülasyon parametrelerinin belirlenmesine yönelik olarak daha önce yapılmış çalışmalarda $b$ değeri 2,964-3,577 arasında hesaplanmıştır (Tablo 2). Söz konusu çalışmalardaki değerler dikkate alındığında, bu çalışmada elde edilen $b$ değerinin daha önceki çalışmalarda elde edilen değerlerle benzerlik gösterdiği ve bu türde büyümenin izometrik veya pozitif allometrik büyüme sergilediği anlaşılmaktadır.

Tablo 2. Ayvacık Barajı ve daha önceki çalışmalarda Alburnus chalcoides popülasyonu için belirlenmiş olan

\begin{tabular}{|c|c|c|c|c|c|c|c|c|}
\hline$b$ & $a$ & $\boldsymbol{L}_{\infty}$ & $k$ & $t_{0}$ & $\Phi^{\prime}$ & $K$ & Çalıșma Alanı & Kaynak \\
\hline & & & & & & 1,09 & Tozanlı Çayı & [7] \\
\hline 2,979 & 0,0144 & & & & & $1,13-1,6$ & Demirköprü Barajı & [8] \\
\hline 3,410 & 0,0029 & & & & & & Volvi Gölü & [15] \\
\hline \multirow[t]{2}{*}{3,330} & 0,0054 & 26,09 & 0,295 & -0.05 & 2,31 & $0,71-1,78$ & Kuş Gölü & [9] \\
\hline & & 41,11 & 0,210 & $-0,37$ & 2,55 & $0,77-1,07$ & Ömerli Barajı & [11] \\
\hline 2,996 & 0,0118 & & & & & & Gönen Çayı & [12] \\
\hline 3,269 & 0,0054 & & & & & $0,92-1,38$ & Tödürge Gölü & [4] \\
\hline
\end{tabular}


Çiçek E., Birecikligil S., Yavuz O., Seçer B., Keskin B

\begin{tabular}{|c|c|c|c|c|c|c|c|c|}
\hline 3,577 & 0,0019 & & & & & $0,89(0,64-1,34)$ & Almus Barajı & [5] \\
\hline 3,006 & 0,017 & & & & & & Kuş Gölü & [6] \\
\hline 2,964 & 0,0118 & & & & & & Çakırköy Deresi & [13] \\
\hline 3,028 & 0,0073 & & & & & & Siahroud Nehri & [16] \\
\hline 3,177 & 0,0048 & & & & & & Gorganroud Nehri & [17] \\
\hline 3,053 & 0,0071 & 32,81 & 0,140 & $-1,38$ & 2,18 & $0,76(0,50-1,56)$ & Ayvacık Barajı & $\mathrm{Bu}$ çalışma \\
\hline
\end{tabular}

Balıklarda büyüme üzerinde abiyotik ve biyotik faktörlerin büyük etkisi bulunmaktadır. $\mathrm{Bu}$ nedenle farklı bölgelerde bulunan popülasyonlar arasında büyüme ve buna bağlı olarak popülasyonun biyo-ekolojik özelliklerinde de farklılıklar görülebilir [35].

Daha önceki çalışmalarda ve bu çalışmada A. chalcoides için belirlenen boy-ağırlık ilişkisi sabitleri, von Bertalanffy büyüme sabitleri, büyüme performans indeksi ve kondisyon faktörü değerleri Tablo 2'de özetlenmiştir. Bu çalışmada hesaplanan $L_{\infty}$ değerinin, Balık ve ark. [9] tarafından Kuş Gölü için hesaplanan değerden büyük ancak Tarkan ve ark. [11] tarafından Ömerli Barajı için hesaplanan değerden küçük olduğu tespit edilmiştir. Bu tür için gözlenen en yüksek boy değerinin Ömerli Barajinda 28,0 cm Tarkan ve ark. [11] ve Tödürge Gölünde 26,2 cm [4] olarak tespit edilmiş olduğu göz önüne alınacak olursa, bu çalışmada elde edilen $L_{\infty}$ değerinin, gözlenen en yüksek değerlerle uyum içerisinde olduğu görülmüştür.

Büyüme performans indeksi ( $\left.\Phi^{\prime}\right)$ Ayvacık Barajı popülasyonu için 2,18 olarak belirlenmiştir. Kuş Gölü [9] ve Ömerli Barajı [11] popülasyonları için $\Phi^{\prime}$ değeri sırasıyla 2,31 ve 2,55 olarak tespit edilmiştir. Su sıcaklığı ile soğukkanlı canlılar olan balıkların metabolik faaliyetleri, beslenmeleri ve bunlara bağlı olarak büyüme oranları arasında sıkı bir ilişki olduğu bilinmektedir. Sıcaklığın yüksek olduğu ortamlarda balıklar daha hızlı büyüme özelliği sergiler ve daha erken cinsi olgunluğa ulaşırken, sıcaklı̆̆ın düşük olduğu ortamlarda büyüme yavaş, cinsi olgunluğa ulaşma yaşı geç olduğundan buna bağlı olarak daha iri cüsseli bireylere rastlanır [35]. Ayvacık Barajı konumu itibariyle 1lıman Akdeniz ikliminin hakim olduğu bir bölgededir. Bu nedenle ilk cinsi olgunluğa ulaşmanın hızlı olması beklenir. Nitekim ilk cinsi olgunluğa ulaşma boyunun karasal iklimin hakim olduğu İç Anadolu Bölgesi göllerinde daha yüksek olarak rapor edilmiştir [26].

Fulton’un Kondisyon Faktörü $(K)$ balıklarda besililik düzeyinin yorumlanmasında yararlanılan bir parametredir. Ayvacık Baraj1 A. chalcoides popülasyonunda bu değerin 0,50 ile 1,56 arasında değişim gösterdiği belirlenmiş ortalama değer ise $0,76 \pm 0,13$ olarak hesaplanmıştır. Daha önceki yapılan çalışmalarda $K$ değerinin 0,71 ile 1,78 arasında değiştiği rapor edilmiş ve ortalama değer 0,9 civarında hesaplanmıştır. Bu çalışmada elde edilen değer daha önceki çalışmalarda elde edilen değerlerin hepsinden daha düşük olarak gerçekleşmiştir. Ancak $K$ değerinin türden türe değişiklik göstereceği gibi, tür içerisinde de yaş, cinsiyet, mevsimsel koşullar (özellikle de sıcaklık), cinsi olgunluk ve üreme, beslenme şartları ve diğer habitat koşullarına göre değişim gösterdiği bilinmektedir [36]. Ancak yine de bu çalışmada elde edilen değerin düşük olması Ayvacık Barajı popülasyonunun düşük bir kondisyona sahip olduğu şeklinde yorumlanabilir.

Çalışmada elde edilen bireylerin Ligula intestinalis (Linnaeus, 1758) paraziti ile enfekte oldukları görülmüştür. Parazit enfeksiyonlarının balıklarda büyüme üzerinde olumsuz etkileri olduğu ve 
bunun yanı sıra balığın karın boşluğu içerisinde büyüyüp gelişen plerocercoid larvanın karın şişliğine sebep olduğu bildirilmektedir [37]. Göllerde belirlenmiş olan $b$ değerinin yüksek çıkması bu duruma da bağlanabilir. Nitekim Jones ve ark. [38]'a göre Anderson ve Gutreuter [39] ile Cone [40] $b$ değerinin balığın vücut şeklindeki değişimlere de bağlı olduğunu bildirmektedirler.

Ayvacık Barajı A. chalcoides popülasyonunda doğal ölüm oranının (M: 0,325) balıkçılık nedeniyle meydana gelen ölüm oranı (F: 0,321) ile hemen hemen aynı düzeyde olduğu anlaşılmıştır (Şekil 3). Bu değerlere bağlı olarak sömürülme oranı (E: 0,5) olarak hesaplanmış ve popülasyondan optimum düzeyde faydalanıldığını göstermektedir. Bu tür üzerinde yapılan daha önceki çalışmalarda Balık ve ark. [9] Kuş Gölü popülasyonunda sömürülme oranını 0,206 olarak bildirmekte ve popülasyon üzerinde balıkçılık baskınının bulunmadığını bildirmektedirler. Ayrıca, Tarkan ve ark. [11] Ömerli Barajı popülasyonunda balıkçılık nedeniyle olan ölümlerin ihmal edilebilir düzeyde düşük olduğunu bildirmektedirler.

Tablo 3. Ayvacık Barajı Alburnus chalcoides popülasyonu için belirlenmiş olan ölüm oranları ve sömürülme düzeyi

\begin{tabular}{llllll}
\hline $\boldsymbol{Z}$ & $\boldsymbol{M}$ & $\boldsymbol{F}$ & $\boldsymbol{E}$ & Habitat & Kaynak \\
0,867 & 0,689 & 0,178 & 0,206 & Kuş Gölü & {$[9]$} \\
& 0,470 & & Ömerli Barajı & {$[11]$} \\
0,646 & 0,325 & 0,321 & 0,497 & Ayvacık Barajı & Bu çalışma \\
\hline
\end{tabular}

\section{Teşekkür}

$\mathrm{Bu}$ çalışma materyalleri Orman ve Su İşleri Bakanlığı tarafından yürütülmekte olan, Ülkemize Özgü Su Kalitesi Ekolojik Değerlendirme Sisteminin Kurulması Projesi kapsamında elde edilmiştir. Bu nedenle, Orman ve Su İşleri Bakanlığı ve DOKAY-ÇED Çevre Mühendisliği Ltd. Şti.’ne teşekkür ederiz.

\section{Kaynaklar}

[1] Kayam S., "Türkiye Ve Diğer Bazı Ülkelerde Rezervuarların Balıkçılık Açısından Yönetim ve Stratejileri”. 1. Balıklandırma ve Rezervuar Yönetimi Sempozyumu, 07-09 Şubat 2006, Antalya, 47-60, 2006.

[2] Balık S., Ustaoğlu M.R., “Türkiye’nin Göl, Gölet ve Baraj Göllerinde Gerçekleştirilen Balıklandırma Çalışmaları ve Sonuçları”, 1. Balıklandırma ve Rezervuar Yönetimi Sempozyumu, 07-09 Şubat 2006, Antalya, 1-10, 2006.

[3] Innal D., “Alien fish species in reservoir systems in Turkey: a review”, Management of Biological Invasions, 3, 115-119, 2012.

[4] Ünver B., Erk’akan F., “Tödürge Gölü’ndeki (Sivas) Alburnus chalcoides (Güldenstädt, 1772)’in Populasyon Yapısı ve Büyüme Özellikleri”, Journal of Fisheries and Aquatic Sciences, 26, 261-266, 2009.

[5] Y1lmaz S., Suiçmez M., “Age Determination and Growth of Alburnus chalcoides (Güldenstädt, 1772) Population Inhabiting Almus Dam Lake (Tokat)”. The Black Sea Journal of Sciences, 1, 7-20, 2010. 
[6] Balaban C., "Manyas Kuş Gölü'nün Balık Faunası ve Türlerin Bazı Biyolojik Özellikleri”, Balıkesir Üniversitesi, Fen Bilimleri Enstitüsü, Yüksek Lisans Tezi, 157s, 2010.

[7] Akyurt I., Sarı M., "Farklı habitatlarda yaşayan Tatlısu kolyoz balığının (Chalcalburnus chalcoides Güldenstaedt, 1772) bazı biyoekolojik özelliklerinin araştırılması", Su Ürünleri Dergisi, 8, 87-101, 1991.

[8] Balık S., Sarı H.M., "Investigations on Growth of Chalcalburnus chalcoides Güldenstaedt, 1772 Population in Demirköprü Dam Lake (Salihli-Turkey)”, XII. National Biology Congress, 6-8 July 1994 Edirne, 1994.

[9] Balık S., Ustaoğlu R., Sarı H.M., Özbek M., "Kuş Gölündeki (Bandırma) Tatlısu Kolyozu (Chalcalburnus chalcoides Güldenstaedt, 1772) popülasyonunun biyolojik özelliklerinin belirlenmesi”, Su Ürünleri Dergisi, 13, 171-182, 1996.

[10] Ünver B., Saraydın S.Ü., "Histological examination of ovarium development of shemaya Chalcalburnus chalcoides living in Lake Tödürge (Sivas/Turkey)”, Folia Zool., 53, 99-106, 2004.

[11] Tarkan A.S., Gaygusuz Ö., Acıpınar H., Gürsoy Ç., "Characteristics of a Eurasian cyprinid, Shemaya, Chalcalburnus chalcoides (Güldenstädt, 1772), in a mesotrophic water reservoir”, Zoology in the Middle East, 35, 49-60, 2005.

[12] Başdemir D., “Gönen Çayı'ndaki (Balıkesir) Tatlısu Kolyozu (Chalcalburnus chalcoides Güldenstaedt, 1772) Populasyonunun Bazı Biyolojik Özelliklerinin İncelenmesi”, Ege Üniversitesi, Fen Bilimleri Enstitüsü, Yüksek Lisans Tezi, 25 s, İzmir, 2007.

[13] Başdemir D., Balık S., İlhan A., "Çakırköy Deresi (Yenice-Çanakkale) Tatlısu Kolyozu, Alburnus chalcoides (Guldenstädt, 1772) Populasyonunun Bazı Biyolojik Özellikleri”, Journal of Fisheries and Aquatic Sciences, 27, 157-160, 2010.

[14] Dirican S., Çilek S., "Condition factors of seven Cyprinid fish species from Çamligöze dam lake on central Anatolia, Turkey”, African Journal of Agricultural Research, 7, 4460-4464, 2012.

[15] Kleanthidis P.K., Sinis A.I., Stergiou K.I., "Length-weight relationship of freshwater fishes in Greece”, ICLARM Naga, 22, 37-41, 1999.

[16] Patimar P., Ezzati M., Sarli J., "Life-history Aspects of Caspian Shemaya Alburnus chalcoides in Two South Caspian Rivers (Siahroud and Gorganroud)", Turkish Journal of Fisheries and Aquatic Sciences, 10, 277-285, 2010.

[17] Rahbar M., Khara H., Khodadoust A., Abbaspour R., "Fecundity and Gonadosomatic Index of Alburnus chalcoides(Guldenstaedt, 1772) Immigrant to Anzali Wetland, Guilan Province, Northern Iran”, World Journal of Fish and Marine Sciences, 5, 449-452, 2013.

[18] Yousefian M., Gezel H.G., Masoud H.F., "Induction of ovulation in endemic Chalcarburnus chalcoides, living in the Caspian Sea, using LRH-Aa combined with metoclopramide", African Journal of Biotechnology, 7, 4199-4201, 2008.

[19] Bagherian A., Rahmani H., "Morphological differentiation between two populations of the Shemaya, Chalcalburnus chalcoides: a geometrical morphometric approach", Zoology in the Middle East, 40, 53-62, 2007. 
[20] Bagherian A., Rahmani H., "Morphological discrimination between two populations of shemaya, Chalcalburnus chalcoides (Actinopterygii, Cyprinidae), using a truss network”, Animal Biodiversity and Conservation, 32.1, 1-8, 2009.

[21] Mohadasi M., Eagderi S., Shabanipour N., Hosseinzadeh M.S., AnvariFar H., Khaefi R., "Allometric body shape changes and morphological differentiation of Shemaya, Alburnus chalcoides (Guldenstadf, 1772), populations in the southern part of Caspian Sea using Elliptic Fourier analysis”, International Journal of Aquatic Biology, 2, 164-171, 2014.

[22] Mohaddasi M., Shabanipour N., Abdolmaleki S., "Morphometric variation among four populations of Shemaya (Alburnus chalcoides) in the south of Caspian Sea using truss network", The Journal of Basic and Applied Zoology, 66, 87-92, 2013.

[23] Bogutskaya N.G., "Contribution to the knowledge of leuciscine fi shes of Asia Minor. Part 2. An annotated checklist of leuciscine fi shes (Leuciscinae, Cyprinidae) of Turkey with descriptions of a new species and two new subspecies”, Mitteilungen aus dem Hamburgischen Zoologischen Museum und Institut, 94, 161-186, 1997.

[24] Geldiay R., Balık S., Türkiye Tatlısu Balıkları. E.Ü. Su Ürünleri Fak. Yayınları No: 46, V. Bask1, 638s, 2007.

[25] Kottelat M., Freyhof J., "Handbook of European freshwater fishes", Publications Kottelat, Cornol, Switzerland, 670p, 2007.

[26] Ünver B., Yıldırım M., "Reproductive biology of Danube bleak, Alburnus chalcoides (Güldenstädt, 1772) in Tödürge Lake (Sivas, Turkey)”, Int. J. Agric. Biol., 13, 976-980, 2011.

[27] Balık S., Sarı H.M., "The investigations on the growth and development of Chalcalburnus chalcoides Güldenstaedt, 1772 in Demirköprü Dam Lake, Salihli-Manisa/Turkey”, XII. National Biology Congress, Hydrobiology Section IV: 113-121, Edirne, 1994.

[28] Fricke R., Bilecenoğlu M., Sarı, H.M., "Annotated checklist of fish and lamprey species (Gnathostomata and Petromyzontomorphi) of Turkey, including a Red List of threatened and declining species”, Stuttgarter Beiträge zur Naturkunde, (A) 706, 1-169, 2007.

[29] Sparre P., Venema S.C., "Introduction to tropical fish stock assessment. Part 1. Manual". FAO Fisheries Technical Paper., No. 306.1 Rev.2, Rome, 407p, 1998.

[30] Ricke W.E., 1975. Computation and interpretation of Biological statistics of fish populations. Bulletin Fishery Research. Board. Can. 191, pp382.

[31] Beverton R.J.H., Holt S.J., "On the Dynamics of Exploited Fish Populations”, Great Britain, Ministry of Agriculture, Fisheries, and Food, Fishery Investigations Series, 19, 533p, 1957.

[32] Pauly D., "On the interrelationships between natural mortality, growth parameters, and mean environmental temperature in 175 fish stocks", Conseil International pour l'Exploration de la Mer, 39, 175-192, 1980.

[33] Anonim., "Çanakkale İli 2012 Yılı İl Çevre Durum Raporu”, Çanakkale Çevre ve Şehircilik II Müdürlüğ̈̈, Çanakkale, 129s, 2013.

[34] Gulland J.A., Rosenberg, A.A., "A review of length-based approaches to assessing fish stocks”, FAO Fisheries Technical Paper, No. 323. Rome, 100p, 1992. 
[35] Sarıhan E., Çiçek E., Toklu B., “Balık Biyolojisine Giriş”, Nobel Kitabevi, Adana, 137s, 2007.

[36] Avşar D., "Balıkçılık Biyolojisi ve Popülasyon Dinamiğii”, Nobel Kitapevi, Adana, 332s, 2005.

[37] İnnal D., Keskin N., Erk’akan F., “Distribution of Ligula intestinalis (L.) in Turkey”, Turkish Journal of Fisheries and Aquatic Sciences, 7, 19-22, 2007.

[38] Jones R.E., Petrell R.J., Pauly D., "Using modified length-weight relationships to assess the condition of fish”, Aquacultural Engineering, 20, 261-276.

[39] Anderson R. O., Gutreuter S. J., "Length weight and associated structural indices”, in: Nielsen, L. A., Johnson, D. L. (Eds.), "Fisheries Techniques” American Fisheries Society, Bethesda, Maryland, pp. 283-300, 1983. 61.

[40] Cone R. S., “The need to reconsider the use of condition indices in fishery science”, Trans. Am. Fish. Soc., 118, 510-514, 1989. 